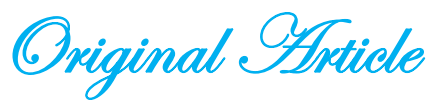

\title{
Obesity and cardiovascular disease risk factors among adult Sudanese
}

Nagwa M Ahmad ${ }^{1}$, Dina A Hassan ${ }^{1}$, El Hussein A M${ }^{1}$, Abdulhadi N. $\mathrm{H}^{* 2}$

\section{Abstract}

Subjects and methods: In this study, the effect of obesity on the development of dyslipidemia, hypertension and glucose intolerance among Sudanese adults attending weight reduction programs was investigated. According to the BMI (Body mass index), 98 overweight/obese and 60 normal weight adults were included. Anthropometric measures were taken, lipid profile and $\mathrm{C}-$ reactive protein (CRP) were determined using commercial kits.

Results: Obesity related dyslipidemia seems to affect overweight/obese males more than females. On the other hand, overweight /obesity among females, not like males, was found to be associated with high blood pressure probably due inflammation, as determined by CRP level.

Conclusion and recommendation: Obesity related dyslipidemia is more prominent among males while obesity related hypertension is a phenomenon among females probably due to release of CRP. We recommend a more detailed study of inflammatory cytokines, in relation to obesity, that may reflect the mass and/or activity of the adipose tissue.

Key words: overweight, dyslipedemia, CVD.

$\mathrm{T}$ The obesity epidemic is a global public health concern that threatens to reduce life expectancy around the world ${ }^{1}$. Excess weight; particularly abdominal obesity, through reduced adiponectin release may cause or exacerbate cardiovascular and metabolic risk factors, including hypertension, dyslipidemia, and type 2 diabetes mellitus ${ }^{2}$. The burden of cardiovascular disease (CVD) seems to increase lately in nearly all developing countries, particularly in urban areas ${ }^{3}$. It is estimated that in the year 2010, CVD will be the leading cause of death in these countries ${ }^{3}$. The major causing factor is probably the ongoing nutrition transition with progressive shift towards westernized food habits with diets high in saturated fats and sugar together with more sedentary life style ${ }^{4}$. The nutrition transition has been documented in South Africa ${ }^{5}$. and Gambia ${ }^{6}$, and Sudan would not be an exception. According to previous studies, hypertension, diabetes and abnormal lipids are related to poor CVD outcomes;

1. The central laboratory, Ministry of Science and technology, Sudan

2. College of Pharmacy, The National Rebat University, Khartoum, Sudan

* Corresponded: E-mail: nasruddina@hotmail.com including myocardial infarction and stroke worldwide and in Africa ${ }^{7}$. Dyslipidemia has emerged as an important CVD risk factor in sub-saharan Africa (SSA). In this study, CVD risk factors that might be determined by obesity were investigated among overweight / obese Sudanese.

\section{Methods:}

\section{Subjects:}

Ninety eight overweight/obese adult subjects (44 men and 54 women of 18 - 62years age range) enrolled in different programs of weight reduction (diet, exercise, or a combination of the two methods), admitted to weight reduction centers were involved in this study. Sixty age matched controls were also included. The study was approved by the Ethics Committee of the Sudan Academy for Science, and written informed consents were obtained from participants before data collection.

A data collection form was completed for each participant including age, ethnic group, occupation, residence, systolic and diastolic blood pressures (SBP, DBP), physical activity and programs of weight reduction. Five $\mathrm{ml}$ fasting venous blood was drawn from each participant. Subjects with inflammation or 
alimentary problems were excluded, as were subjects known to suffer diabetes mellitus or hypertension. None of the subjects in either group was taking medications known to affect carbohydrate and lipid metabolism.

\section{Anthropometric indices:}

Body weight, height, waist and hip circumferences were recorded. Waist-hip ratio $(\mathrm{W} / \mathrm{H})$ and body mass index $(\mathrm{BMI})$ were then calculated. Waist was measured with a non-stretchable tape over the unclothed abdomen at the narrowest point between the lowest rib and the iliac crest $^{8}$. Hip circumference (HC) in centimeters was measured at the level of the greater trochanter using a similar procedure. Two measures were made for each index and the average was used for analyses. High $\mathrm{W} / \mathrm{H}$ ratio, android pattern of fat distribution, was defined as $>1.0$ for men and $>0.85$ for women ${ }^{9}$.

\section{Metabolic variables:}

Using commercial kits, serum total cholesterol (TC) (Biosystems, Spain), triglyceride (TG) (Liquicolor, Germany), High density lipoprotein (HDL) (Spectrum diagnostics, Egypt), Low density lipoprotein (LDL) (Biosystem, Spain), Blood glucose (Crescent diagnostics, KSA) and C-reactive protein (Humatex, Germany) were measured according to the manufacturers' instructions.

\section{Statistical analysis:}

The Pearson's Chi-squared test was used for comparison and a P-value of $<0.05$ was considered indicative of a statistically significant difference. Data analysis was performed using the SPSS 13.0 for Windows software package (SPSS, Chicago, IL).

\section{Results:}

In males, the prevalence of abnormal levels of TG (more than $150 \mathrm{mg} / \mathrm{dl}$ ) was $20.83 \%$ and $20 \%$ in obese and overweight subjects respectively while it was $0 \%$ in normal weight males $(p=0.03)$. The prevalence of low levels of HDL (less than $40 \mathrm{mg} / \mathrm{dl}$ ) was $45.83 \%, 20 \%$ and $6.9 \%$ in obese, overweight and normal weight subjects, respectively $(\mathrm{p}=$ $0.003)$. The prevalence of abnormal levels of total cholesterol (more than $200 \mathrm{mg} / \mathrm{dl}$ ) tends to increase as BMI increases being $0 \%$, $15 \%$ and $41.67 \%$ in normal, overweight and obese males, $(\mathrm{p}=0.000$, Table 1$)$.

Table 1: Prevalence of dyslipidemia and other CVD risk factors among males.

\begin{tabular}{l|llll}
\multicolumn{1}{c|}{ Risk factor } & Normal $(\mathrm{n}=30)$ & Overweight $(\mathrm{n}=20)$ & Obese $(\mathrm{n}=24)$ & $\mathrm{P}$ value* \\
\hline $\mathrm{SBP} \geq 130 \mathrm{mmHg}$ & $1 / 5(20 \%)$ & $6 / 14(42.86 \%)$ & $5 / 16(31.25 \%)$ & 0.614 \\
$\mathrm{DBP} \geq 85 \mathrm{mmHg}$ & $1 / 5(20 \%)$ & $4 / 14(28.57 \%)$ & $4 / 16(25 \%)$ & 0.928 \\
$\mathrm{FBG} \geq 110 \mathrm{mg} / \mathrm{dl}$ & $1 / 30(3.44 \%)$ & $4 / 20(20 \%)$ & $6 / 24(25 \%)$ & 0.063 \\
$\mathrm{TG} \geq 150 \mathrm{mg} / \mathrm{dl}$ & $0 / 30(0 \%)$ & $4 / 20(20 \%)$ & $5 / 24(20.83 \%)$ & 0.03 \\
$\mathrm{TC} \geq 200 \mathrm{mg} / \mathrm{dl}$ & $0 / 30(0 \%)$ & $3 / 20(15 \%)$ & $10 / 24(41.67 \%)$ & 0.000 \\
$\mathrm{HDL} \leq 40 \mathrm{mg} / \mathrm{dl}$ & $2 / 30(6.9 \%)$ & $4 / 20(20 \%)$ & $11 / 24(45.83 \%)$ & 0.003 \\
$\mathrm{LDL} \geq 130 \mathrm{mg} / \mathrm{dl}$ & $7 / 30(24.14 \%)$ & $9 / 20(45 \%)$ & $10 / 24(41.67 \%)$ & 0.208 \\
$\mathrm{CRP} \geq 8.2$ & $1 / 30(3.44 \%)$ & $1 / 20(4 \%)$ & $2 / 24(8.33 \%)$ & 0.719
\end{tabular}

Among female subjects, the prevalence of abnormal levels of CRP ( more than $8.2 \mathrm{mg}$ $/ 1$ ) were found to be $26.47 \%$ and $10 \%$ in obese and overweight females, respectively, while it was $0 \%$ in normal weight females ( $p$ $=0.007)$ The prevalence of elevated SBP (more than $130 \mathrm{~mm} \mathrm{Hg}$ ) was found to be $50 \%$, $25 \%$, and $0 \%$ in obese, overweight and normal weight females respectively $(\mathrm{p}=0.001)$. The prevalence of high DBP (more than $85 \mathrm{~mm} \mathrm{Hg}$ ) increased with BMI being $0 \%, 25 \%$ and $37.5 \%$ in normal, overweight and obese females, respectively ( $\mathrm{p}$ $=0.004)$.The prevalence of low HDL concentration (less than $50 \mathrm{mg} / \mathrm{dl}$ ) also increases as BMI increases $(p=0.003)$. (Table 2). 
Table 2: Prevalence of CVD risk factors among females.

\begin{tabular}{c|cccc} 
Risk factors & Normal $(\mathrm{n}=30)$ & Overweight $(\mathrm{n}=20)$ & Obese $(\mathrm{n}=34)$ & $\mathrm{P}$ value* \\
\hline $\mathrm{SBP} \geq 130 \mathrm{mmHg}$ & $0 / 30(0 \%)$ & $2 / 8(25 \%)$ & $4 / 8(50 \%)$ & 0.001 \\
$\mathrm{DBP} \geq 85 \mathrm{mmHg}$ & $0 / 30(0 \%)$ & $2 / 8(25 \%)$ & $3 / 8(37.5 \%)$ & 0.004 \\
$\mathrm{FBG} \geq 110 \mathrm{mg} / \mathrm{dl}$ & $0 / 30(0 \%)$ & $2 / 20(10 \%)$ & $5 / 34(14.7 \%)$ & 0.100 \\
$\mathrm{TG} \geq 150 \mathrm{mg} / \mathrm{dl}$ & $0 / 30(0 \%)$ & $2 / 20(10 \%)$ & $3 / 34(8.82 \%)$ & 0.225 \\
$\mathrm{Tchol} \geq 200 \mathrm{mg} / \mathrm{dl}$ & $1 / 30(3.33 \%)$ & $4 / 20(20 \%)$ & $2 / 34(5.88 \%)$ & 0.09 \\
$\mathrm{HDL} \leq 50 \mathrm{mg} / \mathrm{dl}$ & $0 / 30(0 \%)$ & $4 / 20(20 \%)$ & $11 / 24(32.4 \%)$ & 0.003 \\
$\mathrm{LDL} \geq 130 \mathrm{mg} / \mathrm{dl}$ & $7 / 30(23.33 \%)$ & $7 / 20(35 \%)$ & $12 / 34(35.29 \%)$ & 0.53 \\
$\mathrm{CRP} \geq 8.2 \mathrm{mg} / \mathrm{l}$ & $0 / 30(0 \%)$ & $2 / 20(10 \%)$ & $9 / 34(26.47 \%)$ & 0.007
\end{tabular}

*Pearson's Chi-square test

The frequency of risky SBP (64\%) was higher among males with gynoid pattern of fat distribution compared to those with android pattern $(23 \%), p=0.018$. The pattern of fat distribution among males is also affecting the frequency of low levels of HDL being $64 \%$ and $30 \%$ among gynoid and android males respectively, $p=0.03$, (Table 3 ).

Table 3: Prevalence of CVD risk factors among males with android or gynoid pattern of fat distribution:

\begin{tabular}{c|ccc} 
Risk factors & Android $(\mathrm{n}=61)$ & Gynoid $(\mathrm{n}=11)$ & $\mathrm{P}$ value* \\
\hline $\mathrm{SBP} \geq 130 \mathrm{mmHg}$ & $6 / 26(23 \%)$ & $7 / 11(64 \%)$ & 0.018 \\
$\mathrm{DBP} \geq 85 \mathrm{mmHg}$ & $5 / 26(19.2 \%)$ & $5 / 11(45 \%)$ & 0.100 \\
$\mathrm{FBG} \geq 110 \mathrm{mg} / \mathrm{dl}$ & $8 / 61(13 \%)$ & $2 / 11(18 \%)$ & 0.655 \\
$\mathrm{TG} \geq 150 \mathrm{mg} / \mathrm{dl}$ & $5 / 61(8.2 \%)$ & $3 / 11(27 \%)$ & 0.060 \\
$\mathrm{~T}$ chol $\geq 200 \mathrm{mg} / \mathrm{dl}$ & $9 / 61(15 \%)$ & $3 / 11(27 \%)$ & 0.310 \\
$\mathrm{HDL} \leq 40 \mathrm{mg} / \mathrm{dl}$ & $18 / 61(30 \%)$ & $7 / 11(64 \%)$ & 0.030 \\
$\mathrm{LDL} \geq 130 \mathrm{mg} / \mathrm{dl}$ & $23 / 61(38 \%)$ & $4 / 11((36 \%)$ & 0.933 \\
$\mathrm{CRP} \geq 8.2 \mathrm{mg} / \mathrm{l}$ & $3 / 61(5 \%)$ & $1 / 11(9 \%)$ & 0.578
\end{tabular}

*Pearson's Chi-square test

The frequency of risky SBP and DBP was higher among females with gynoid pattern of fat distribution ( $57 \%$ and $57 \%$, prespectively) compared to those with android pattern $(22 \%$ and $11.0 \%$, respectively), $\mathrm{p}=0.015$ and 0.05 , respectively. The pattern of fat distribution among females is also affecting the frequency of CRP concentration being $22 \%$ and $5 \%$ among gynoid and android females respectively $(\mathrm{p}=0.017$, Table 4).

Table 4: Prevalence of CVD risk factors among females with android or gynoid pattern of fat distribution:

\begin{tabular}{c|ccc} 
Risk factors & Android $(\mathrm{n}=44)$ & Gynoid $(\mathrm{n}=41)$ & P value* \\
\hline $\mathrm{SBP} \geq 130 \mathrm{mmHg}$ & $2 / 9(22 \%)$ & $4 / 7(57 \%)$ & 0.015 \\
$\mathrm{DBP} \geq 85 \mathrm{mmHg}$ & $1 / 9(11 \%)$ & $4 / 7(57 \%)$ & 0.050 \\
$\mathrm{FBG} \geq 110 \mathrm{mg} / \mathrm{dl}$ & $2 / 44(5 \%)$ & $4 / 41(10 \%)$ & 0.350 \\
$\mathrm{TG} \geq 150 \mathrm{mg} / \mathrm{dl}$ & $1 / 44(2 \%)$ & $1 / 41(2.4 \%)$ & 0.960 \\
$\mathrm{~T}$ chol $\geq 200 \mathrm{mg} / \mathrm{dl}$ & $5 / 44(11 \%)$ & $6 / 44(14 \%)$ & 0.650 \\
$\mathrm{HDL} \leq 50 \mathrm{mg} / \mathrm{dl}$ & $3 / 44(7 \%)$ & $2 / 41(5 \%)$ & 0.700 \\
$\mathrm{LDL} \geq 130 \mathrm{mg} / \mathrm{dl}$ & $12 / 44(27 \%)$ & $17 / 41(41 \%)$ & 0.168 \\
$\mathrm{CRP} \geq 8.2 \mathrm{mg} / 1$ & $2 / 44(5 \%)$ & $9 / 41(22 \%)$ & 0.017
\end{tabular}

*Pearson's Chi-square test 


\section{Discussion:}

Prevalence of risky high levels of TG $(\geq 150$ $\mathrm{mg} / \mathrm{dl})$, TC $(\geq 200 \mathrm{mg} / \mathrm{dl})$, and low levels of HDL $(\leq 40 \mathrm{mg} / \mathrm{dl})$ was found to be significantly higher among overweight and obese males (TG: $20 \%$ and $20.3 \%$, TC: $15 \%$ and 41.6\%, HDL: $20 \%$ and $45.8 \%$, respectively) compared to normal weight males (TG: $0.0 \%$, TC: $0.0 \%$ and HDL: $6.9 \%$,). Individuals with greater degrees of central adiposity are expected to develop the metabolic syndrome more frequently than do those with a peripheral body fat distribution ${ }^{10}$. This is consistent with our results since $84.7 \%$ of males in this study are having android pattern of fat distribution. Due to its proatherogenic potential hypertriglyceridemia is considered an independent risk factor for coronary artery disease ${ }^{11}$. Hypertriacylglyceridemia increases the incidence of cardiovascular disease by $32 \%$ in men and $76 \%$ in women, independent of plasma HDL-C levels ${ }^{12}$. In adults, as in children, several 'adipocytokines' have been related to adiposity indices as well as to insulin resistance. Interleukin-6 (IL-6) is one of the inflammatory cytokine released by adipose tissue and its level is increased in obesity $^{13}$. IL-6 stimulates the hepatic production of C-reactive protein and this can explain the state of inflammation associated with obesity, and could mediate, at least partially, obesity-related insulin resistance ${ }^{13}$. This scenario does not seem to apply to males in this study since the mean level of CRP was found to be comparable among male groups. Insulin resistance has been hypothesized to play a major role in dyslipidemia in individuals with normal glucose tolerance, as well as in those with impaired glucose tolerance and type 2 diabetes ${ }^{14}$. Lipid abnormalities have also been reported in obese adults, who have elevated triglycerides and LDL cholesterol and low levels of HDL cholesterol $^{15}$. Similar lipid profiles have been reported in obese and non obese adults with type 2 diabetes, in obese normoglycemic adults, and in non obese adults with impaired glucose tolerance ${ }^{16}$. According to our results, there is no evidence of glucose intolerance in males or females study groups. Therefore, the dyslipidemia seen in our male study group is not related to release of inflammatory factors or the consequent insulin resistance and remains to be investigated. In females, not like males, obesity seems to affect blood pressure and HDL more than other lipids. Prevalence of both systolic and diastolic hypertension was significantly higher among overweight $(25 \%$ and $25 \%)$ and obese $(50 \%$ and $37.5 \%$ ) compared to normal weight females $(0.0 \%$ and $0.0 \%)$. Low levels HDL $(\leq$ $50 \mathrm{mg} / \mathrm{dl}$ ) were significantly more prevalent among overweight and obese compared to normal weight females.TG levels of $\geq 150$ $\mathrm{mg} / \mathrm{dl}$ were higher among the overweight group compared to obese and normal weight females, however, differences were not significant. In contrast to males, the effect of WHR on lipid profiles and blood pressure was not evident among females. Normal weight females, showing no evidence of dyslipidemia or hypertension had comparable WHR to obese and both had significantly higher WHR than overweight females. However, previous reports have shown abdominal obesity as positively associated with metabolic syndrome in Benin and with increased risk of heart disease in Congo ${ }^{17,18}$. In contrast to males among whom the mean CRP level, though increases with BMI, does not reach to risky high levels as seen among females (obese males had mean CRP of 1.64 $\mathrm{mg} / \mathrm{l}$ while females had mean CRP of 7.7 $\mathrm{mg} / \mathrm{l})$. This is an indicator of inflammation among overweight/obese females in our study group. Although the etiology of hypertension is multifactorial, complex and poorly understood, nevertheless, recently it has been suggested that inflammation of the arterial wall is implicated in the development of endothelial dysfunction which leads to hypertension ${ }^{19}$. The CRP level has been shown to be an independent risk factor for the development of hypertension ${ }^{20}$. The release of higher levels of CRP in obese females than males in this study may suggest a higher mass 
and/or more active adipose tissue among females compared to males.

\section{Conclusion:}

In conclusion, obesity seems to cause dyslipidemia among sudanese adult males but not females among whom hypertension is a more evident outcome, propably due to increased CRP levels.

Aknowlegements: Our sincere gratitude to the staff and members of International Health Club at Burri, Khartoum, for their cooperation.

\section{References:}

1. Olshansky SJ, Passaro DJ, Hershow RC et al. A potential decline in life expectancy in the United States in the 21st century. N Engl J Med 2005; 352: 1138 1145 .

2. Adiponectin MY: A key player in obesity related disorders. Curr Pharm Des 2010; 16 (17): 1896 - 1901.

3. Boutayeb A and Boutayeb S. The burden of non communicable diseases in developing countries. Int $\mathrm{J}$ Equity Health. 2005 14;4(1):2.

4. Popkin BM. The shift in stages of the nutrition transition in the developing world differs from past experiences! Public Health Nutr. 2002; 5(1A):205-14.

5. Vorster HH, Venter CS, Wissing MP et al. The nutrition and health transition in the North West Province of South Africa: a review of the THUSA (Transition and Health during Urbanisation of South Africans) study. Publ Hlth Nutr. 2005;8(5):480-90.

6. Siervo M, Grey P, Nyan OA et al. Urbanization and obesity in The Gambia: a country in the early stages of the demographic transition. Eur J Clin Nutr. 2006; 60(4):455-63.

7. Steyn K, Sliwa K, Hawken S et al. INTERHEART Investigators in Africa: Risk factors associated with myocardial infarction in Africa: the INTERHEART Africa study. Circulation 2005; 112(23):3536-3540. 8. McCarthy HD, Ellis SM and Cole TJ. Central overweight and obesity in British youth aged 11-16 years: cross sectional surveys of waist circumference. BMJ 2003; 326(7390):624.

9. Pischon T, Boeing H, Hoffmann K et al., General and abdominal adiposity and risk of death in Europe. $\mathrm{N}$ Engl J Med. 2008; 359(20):2105-20.

10. Kissebah AH and Krakower GR. Regional adiposity and morbidity. Physiol Rev. 1994; 74:761811.

11. Hopkins PN, Wu LL, Hunt SC et al. Plasma triglycerides and type III hyperlipidemia are independently associated with premature familial coronary artery disease. J Am Coll Cardiol 2005; 45:1003-12.

12. Hokanson JE. Hypertriglyceridemia and risk of coronary heart disease. Curr Cardiol Rep 2002; 4:48893.

13. Matsuzawa Y. White adipose tissue and cardiovascular disease. Best Pract Res Clin Endocrinol Metab 2005; 19: 637-647.

14. Laakso $\mathrm{M}$ and Barrett-Connor E. Asymptomatic hyperglycemia is associated with lipid and lipoprotein changes favoring atherosclerosis. Arteriosclerosis. 1989; 9:665-672.

15. Evans DJ, Hoffmann RG, Kalkhoff RK et al. Relationship of body fat topography to insulin sensitivity and metabolic profiles in premenopausal women. Metabolism. 1984; 33:68-75.

16. Zavaroni I, Dall'Aglio E, Alpi O et al. Evidence for an independent relationship between plasma insulin and concentration of high density lipoprotein cholesterol and triglyceride. Atherosclerosis. 1985;55: 259-266.

17. Ntandou G, Delisle H, Agueh V et al. Abdominal obesity explains the positive rural-urban gradient in the prevalence of the metabolic syndrome in Benin, West Africa. Nutr Res 2009; 29(3):180-189.

18. Longo-Mbenza B, Mambune HF, Kasiamm JB et al. Relationship between waist circumference and cholesterol in Central Africans with congestive heart failure. West Afr J Med 2007; 26(3):183-190.

19. Boos CJ and Lip GY. Is hypertension an inflammatory process? Curr Pharm Des. 2006;12(13):1623-35.

20. Bautista LE, López-Jaramillo P, Vera LM et al. Is C-reactive protein an independent risk factor for essential hypertension? J Hypertens. 2001;19(5): 857-61. 
